\title{
KEPATUHAN TERHADAP PENGOBATAN PADA PASIEN HIPERTENSI DENGAN KOMPLIKASI DIABETES MELITUS DI PUSKESMAS YOGYAKARTA
}

\section{ADHERENCE OF MEDICATION THERAPY IN HYPERTENSIVE PATIENTS WITH DIABETES MELLITUS AT HEALTH CENTER YOGYAKARTA}

\author{
Mufti Alifia Rahmadani, Andriana Sari* \\ Fakultas farmasi, Universitas Ahmad Dahlan Yogyakarta \\ Jl. Prof. Dr. Soepomo Janturan Umbulharjo Yogyakarta 55164 \\ *Penulis Korespodensi, email: andriesari@gmail.com
}

\begin{abstract}
ABSTRAK
Kepatuhan terhadap pengobatan mempengaruhi keberhasilan terapi pasien. Tujuan dalam penelitian ini untuk mengetahui kepatuhan pengobatan pada pasien hipertensi dengan komplikasi diabetes melitus di Puskesmas wilayah Kota Yogyakarta. Penelitian observasional ini menggunakan pendekatan desain cross sectional. Pengambilan data dilakukan dengan menggunakan kuesioner Medication Adherence Report Scale (MARS). Responden dalam penelitian ini adalah semua pasien hipertensi dengan komplikasi diabetes melitus yang menjalani rawat jalan di 5 Puskesmas wilayah Kota Yogyakarta pada periode bulan November 2017 - Januari 2018. Analisa distribusi frekuensi digunakan untuk mengetahui kepatuhan terhadap pengobatan pasien. Penelitian ini melibatkan 44 responden dari 5 Puskesmas wilayah Kota Yogyakarta. Puskesmas yang digunakan sebagai tempat pengambilan data yaitu Puskesmas Ngampilan, Puskesmas Mergangsan, Puskesmas Kotagede I, Puskesmas Danurejan I dan Puskesmas Gondokusuman II. Data karakteristik responden tertinggi pada perempuan $(63,6 \%)$, kelompok umur 60-79 tahun $(75,0 \%)$, berpendidikan tamat SLTA/Sederajat (40,9\%), dan pasien tidak bekerja (54,5\%). Hasil analisa kepatuhan pasien diketahui $59,1 \%$ patuh dan $40,9 \%$ tidak patuh dalam pengobatannya. Kesimpulan dari penelitian ini adalah sebagian besar pasien hipertensi dengan komplikasi diabetes melitus di puskesmas wilayah Kota Yogyakarta patuh terhadap pengobatannya.
\end{abstract}

Kata kunci: Kepatuhan, Hipertensi, Diabetes Melitus, MARS

\section{ABSTRACT}

Adherence to treatment affect the outcome of therapy. This study aims to assess the adherence of medicine therapy on hypertensive patients with diabetes mellitus at health centre in Yogyakarta. This observational study used cross sectional approach design. Medication Adherence Report Scale (MARS) was used to collect the data. Respondents in this study were all hypertensive patients with diabetes mellitus who underwent outpatient care in 5 health centers in Yogyakarta city during the month of November 2017 to January 2018. Analysis of frequency distribution was used to determine 
adherence to medication treatment. A total of 44 respondents from 5 health centers in Yogyakarta city were involved in this study. Data collection was conducted at the Ngampilan Health Center, Mergangsan Health Center, Kotagede I Health Center, Danurejan I Health Center and Gondokusuman II Health Center. The highest characteristics of the respondents were women (63.6\%), 60-79 years (75.0\%), graduated High school / equivalent (40.9\%), and unemployment (54.5\%). The results of the adherence analysis was revealed 59.1\% of the respondents were adherent and $40.9 \%$ were not adherent to their medication. The conclusion of this study showed the majority patients hypertension with diabetes mellitus at health centre in Yogyakarta were adherence to their medication therapy.

Keywords: Adherence, Hypertension, Diabetes Mellitus, MARS

\section{PENDAHULUAN}

Hipertensi merupakan salah satu masalah besar dan serius bagi kesehatan masyarakat di seluruh dunia. World Health Statistics tahun 2012 melaporkan bahwa sekitar 51\% dari kematian akibat stroke dan 45\% dari penyakit jantung koroner disebabkan oleh hipertensi. Di Indonesia, kasus hipertensi cukup tinggi yakni sebesar $25,8 \%$ yang terjadi pada umur $\geq 18$ tahun dan yang terdiagnosis oleh tenaga kesehatan atau mengkonsumsi obat hanya sebesar 9,5\% (Kemenkes RI, 2014).

Hasil Riset Kesehatan Dasar (Riskesdas) tahun 2013 menunjukkan bahwa Provinsi DIY dengan prevalensi hipertensi umur $\geq 18$ menduduki urutan ketiga tertinggi berdasarkan wawancara. Data dari Dinas Kesehatan Kota Yogyakarta menunjukkan bahwa hipertensi menjadi urutan pertama dari 10 besar pola penyakit di puskesmas Kota Yogyakarta dengan total kejadian hipertensi mencapai 114.449 kasus (Dinas Kesehatan Kota Yogyakarta, 2014).

Hipertensi lazim terjadi pada penderita diabetes melitus. Penelitian di Nigeria membuktikan bahwa penderita hipertensi dua kali lebih umum terjadi pada penderita diabetes. Sebanyak 54,2\% responden penelitian tersebut merupakan penderita diabetes melitus dan hipertensi (Unadike et al., 2011). Komplikasi hipertensi dan diabetes melitus akan menjadi awal dari komplikasi lain yang menyebabkan berbagai kerusakan pada organ ginjal, jantung dan otak (Kolo et al., 2012).

Kepatuhan terhadap pengobatan adalah faktor utama dari outcome terapi (Morello et al., 2011). Oleh karena itu pengukuran tingkat kepatuhan penggunaan obat sangat penting dilakukan untuk mengetahui keberhasilan pengobatan. Medication Adherence Report Scale (MARS) merupakan instrumen yang digunakan untuk mengukur tingkat kepatuhan terapi obat yang memiliki 5 item pertanyaan dan telah divalidasi pada pasien hipertensi tanpa komplikasi di puskesmas wilayah Kota Yogyakarta (Sari et al., 2015).

Pasien yang tidak patuh dalam jangka panjang dapat menyebabkan berbagai penyakit komplikasi. Untuk itu diperlukan penelitian tentang gambaran kepatuhan terhadap pengobatan pada pasien hipertensi dengan komplikasi diabetes melitus di Puskesmas wilayah Kota Yogyakarta. 


\section{METODE PENELITIAN}

\section{Bahan dan Alat}

Rancangan penelitian cross sectional pada pasien hipertensi dengan komplikasi diabetes melitus di 5 Puskesmas wilayah Kota Yogyakarta dengan periode penelitian bulan November 2017-Januari 2018. Kuesioner MARS digunakan untuk mengetahui kepatuhan terapi obat.

\section{Jalannya Penelitian}

Responden yang diikutsertakan pada penelitian ini adalah pasien hipertensi dengan komplikasi diabetes melitus di 5 puskesmas wilayah Kota Yogyakarta diantaranya Puskesmas Ngampilan, Puskesmas Mergangsan, Puskesmas Kotagede I, Puskesmas Danurejan I, dan Puskesmas Gondokusuman II yang telah didiagnosa hipertensi dengan komplikasi diabetes melitus yang memiliki kode ICD (International Statistical Classification of Diseases and Related Health Problems) I10 (hipertensi Esensial) dengan E10 (diabetes melitus tipe 1) atau E11 (diabetes melitus tipe 2) serta memenuhi kriteria inklusi dan eksklusi.

Kriteria inklusi penelitian ini adalah pasien berjenis kelamin laki-laki atau perempuan, pasien berusia $>18$ tahun, pasien yang sudah mendapat pengobatan hipertensi dan diabetes melitus minimal 3 bulan dan bersedia menjadi responden penelitian. Kriteria eksklusi penelitian ini adalah pasien hipertensi dengan komplikasi diabetes melitus yang sedang hamil dan menyusui dan pasien hipertensi dengan komplikasi diabetes melitus yang memiliki gangguan ginjal dan gangguan hati.

Analisa distribusi frekuensi digunakan untuk mengetahui kepatuhan terhadap pengobatan pada pasien hipertensi dengan komplikasi diabetes melitus di Puskesmas wilayah Kota Yogyakarta.

\section{HASIL DAN PEMBAHASAN}

Karakteristik Responden

Responden diambil secara purposive sampling dengan mempertimbangkan kriteria inklusi dan eksklusi. Responden yang menderita hipertensi dengan komplikasi diabetes melitus yang digunakan sebagai resoponden penelitian ini yakni pasien yang menjalani rawat jalan selama bulan November 2017-Januari 2018 di 5 puskesmas wilayah Kota Yogyakarta di antaranya Puskesmas Ngampilan, Puskesmas Mergangsan, Puskesmas Kotagede I, Puskesmas Danurejan I, dan Puskesmas Gondokusuman II sebanyak 44 pasien. Data distribusi karakteristik pasien disajikan pada tabel I.

\section{Jenis Kelamin Responden}

Hasil penelitian menunjukkan bahwa responden yang menderita hipertensi dengan komplikasi diabetes melitus lebih banyak diderita oleh perempuan $(63,6 \%)$ dibandingkan laki-laki (36,4\%). Pada penderita hipertensi dengan komplikasi diabetes melitus yang menyebutkan bahwa perempuan $(75,4 \%)$ lebih banyak menderita 
hipertensi dengan komplikasi diabetes melitus dibandingkan dengan laki-laki (24,6\%) (Bolarinwa et al., 2016).

Hal ini membuktikan bahwa jenis kelamin menjadi salah satu faktor yang berhubungan dengan tekanan darah. Perempuan usia diatas 45 tahun akan mengalami menopause sehingga akan terjadi peningkatan resiko terkena hipertensi. Pada postmenopause kadar hormon estrogen lebih rendah daripada perempuan premenopause. Hormon estrogen berperan dalam meningkatkan kadar HDL (high density lipoprotein), tingginya kadar HDL dapat mempengaruhi terjadinya proses aterosklerosis dan menyebabkan tekanan darah menjadi tinggi (Anggraini et al., 2009).

Tabel I. Distribusi karakteristik responden hipertensi dengen komplikasi diabetes melitus di puskesmas wilayah kota yogyakarta periode bulan November 2017-Januari 2018

\begin{tabular}{lcc}
\hline \multicolumn{1}{c}{ Karakteristik } & Jumlah Pasien & $\mathbf{( \% )}$ \\
\hline Jenis Kelamin & & \\
Laki-laki & 16 & $36,4 \%$ \\
Perempuan & 28 & $63,6 \%$ \\
\hline Usia (tahun) & & \\
$40-59$ & 10 & $22,7 \%$ \\
$60-79$ & 33 & $75,0 \%$ \\
$\geq 80$ & 1 & $2,3 \%$ \\
\hline Pendidikan & & \\
Tidak tamat SD & 14 & $31,8 \%$ \\
Tamat SLTP/sederajat & 7 & $15,9 \%$ \\
Tamat SLTA/sederajat & 18 & $40,9 \%$ \\
Tamat Akademi & 2 & $4,5 \%$ \\
Tamat S1 & 3 & $6,8 \%$ \\
\hline Pekerjaan & & \\
Tidak Bekerja & 24 & $54,5 \%$ \\
Pensiunan & 7 & $15,9 \%$ \\
Pegawai Swasta & 2 & $4,5 \%$ \\
Wiraswasta & 7 & $15,9 \%$ \\
Lainnya & 4 & $9,1 \%$ \\
\hline
\end{tabular}

Usia Responden

Karakteristik responden berdasarkan usia dikelompokkan menjadi rentang usia 40-59 tahun, 60-79 tahun, dan $\geq 80$ tahun. Responden yang menderita hipertensi dengan komplikasi diabetes melitus di 5 puskesmas wilayah Kota Yogyakarta yang berumur 40-59 tahun sebanyak 10 orang (22,7\%), pada kelompok 60-79 tahun sebanyak 33 orang $(75,0 \%)$, dan pada kelompok usia $\geq 80$ tahun sebanyak 1 orang $(2,3 \%)$.

Berdasarkan hasil tersebut, dapat dilihat bahwa mayoritas responden penelitian berada diusia antara 60-79 tahun. Hal ini sejalan dengan penelitian yang dilakukan oleh Lestari (2015) dan Aulia (2016) yang menemukan bahwa penderita hipertensi di Indonesia terbanyak berada pada usia diatas 60 tahun. Hal ini karena seiring bertambahnya usia menyebabkan banyak perubahan fisiologis dan fungsional sehingga membuat tubuh lebih rentan terkena penyakit salah satunya yaitu hipertensi (Carvalho et al., 2012). 
Pendidikan Responden

Karakteristik responden berdasarkan tingkat pendidikan pasien dikelompokkan menjadi 5 kategori, yaitu tamat SD, tamat SLTP/sederajat, tamat SLTA/sederajat, tamat S1, dan tamat Akademi. Berdasarkan hasil penelitian, sebagian besar pasien berpendidikan tamat SLTA/Sederajat sebanyak 18 orang $(40,9 \%)$, kemudian tamat SD sebanyak 14 orang $(31,8 \%)$ dan tamat SLTA sebanyak 7 orang $(15,9 \%)$. Tingkat pendidikan tamat S1 (3 orang) dan tamat Akademi (2 orang) memiliki jumlah persentase terkecil $(6,8 \%$ dan $4,5 \%)$. Sebagian besar $(39,7 \%)$ penderita hipertensi dengan komplikasi diabetes melitus tidak memahami penyakit yang dideritanya (no education) (Bolarinwa et al., 2016). Tingkat pendidikan pasien berkaitan langsung dengan masalah yang dihadapi setiap pasien sehingga dapat dijadikan upaya untuk meningkatkan kepatuhan dan kualitas hidup pasien (Saputri et al., 2018). Hal ini membuktikan bahwa tingkat pendidikan menjadi faktor penting yang dapat mempengaruhi pemahaman terhadap informasi tentang penyakit yang diderita dan kepatuhan dalam pengobatan.

Pekerjaan Responden

Karakteristik responden berdasarkan pekerjaan diperoleh sebanyak 24 orang $(54,5 \%)$ pasien tidak bekerja, 7 orang $(15,9 \%)$ sebagai pensiunan, 2 orang $(4,5 \%)$ bekerja sebagai pegawai swasta, 7 orang $(15,9 \%)$ bekerja sebagai wiraswasta, dan sebanyak $4(9,1 \%)$ memiliki pekerjaan lainnya diluar kategori yang telah ditentukan. Hasil penelitian ini menunjukkan sebagian besar pasien hipertensi dengan komplikasi diabetes melitus yang menjalani rawat jalan di 5 puskesmas wilayah Kota Yogyakarta tidak bekerja. Serupa dengan penelitian Fauzia (2016), 34,6\% responden penderita hipertensi memiliki pendidikan terakhir tamat SLTA/Sederajat. Usia diatas 60 tahun mayoritas tidak bekerja dan pendapatan terbesar hanya berasal dari jaminan sosial dan pensiunan serta pekerjaan yang mereka lakukan (Annisa, 2013).

Kepatuhan Terapi

Pengukuran kepatuhan terapi pada penelitian ini menggunakan kuesioner MARS (Medication Adherence Report Scale) yang mudah digunakan dalam pelayanan kesehatan. Kuesioner ini memiliki 5 pertanyaan dengan jawaban selalu, sering, kadangkadang, jarang dan tidak pernah. Setiap item pertanyaan dinilai dengan skor 1-5. Kategori penilaian menggunakan kuesioner MARS ini dibagi menjadi 2, yaitu kategori patuh dengan total skor 25 dan tidak patuh dengan total skor $<25$. Distribusi kepatuhan pada pasien hipertensi dengan komplikasi diabetes melitus dapat dilihat pada tabel II.

Penelitian kepatuhan diperoleh dari 44 responden yang termasuk dalam kategori patuh sebanyak 26 pasien $(59,1 \%)$ dan kategori tidak patuh sebanyak 18 pasien $(40,9 \%)$. Berdasarkan hasil tersebut menunjukkan bahwa responden yang patuh lebih banyak dibandingkan yang tidak patuh. Hasil penelitian lain yang dilakukan di Indonesia diketahui $37,2 \%$ penderita hipertensi tidak mengkonsumsi obat antihipertensinya dikarenakan faktor pendidikan, pekerjaan dan usia (Darnindro et al., 2017). Oleh karena 
itu pengukuran tingkat kepatuhan penggunaan obat sangat penting dilakukan untuk mengetahui keberhasilan pengobatan.

Tabel II. Distribusi kepatuhan terapi pada pasien hipertensi dengan komplikasi diabetes melitus di Puskesmas Wilayah Kota Yogyakarta menggunakan kuesioner MARS

\begin{tabular}{lcc}
\hline Kepatuhan & $\begin{array}{c}\text { Jumlah } \\
\text { Responden }\end{array}$ & \% \\
\hline Patuh & 26 & $59,1 \%$ \\
Tidak Patuh & 18 & $40,9 \%$ \\
Total & 44 & $100 \%$ \\
\hline
\end{tabular}

Meskipun pengobatan sudah sesuai dengan standar terapi yang ada, jika tingkat kepatuhan dalam mengkonsumsi obat sangat minim maka akan menyebabkan kesehatan semakin memburuk. Sebuah penelitian lain di Lebanon yang dilakukan pada pasien hipertensi menunjukkan penurunan tekanan darah kurang dari 120/80 $\mathrm{mmHg}$ lebih banyak terjadi pada pasien yang patuh $(67,1 \%)$ dibandingkan pasien yang tidak patuh (32,9\%) (Alhaddad et al., 2016). Hal tersebut menggambarkan pengukuran tingkat kepatuhan pada individu untuk memperbaiki kualitas dan tujuan pengobatannya.

Hasil penelitian ini juga sejalan dengan penelitian Zyoud (2013) yang melaporkan $63 \%$ dari total responden memiliki tingkat kepatuhan sedang - tinggi yang diukur dengan menggunakan kuisioner yang berbeda yaitu kuesioner MMAS. Penelitian lain membuktikan bahwa sebagian besar penderita hipertensi dengan komplikasi diabetes melitus memiliki kepatuhan yang tinggi (49,1\%) (Bolarinwa et al., 2016). Banyaknya responden yang memiliki tingkat kepatuhan yang baik, diharapkan dapat menjadi motivasi bagi para penderita hipertensi dengan/tanpa komplikasi lainnya agar dapat meningkatkan dan mempertahankan kepatuhan dalam mengkonsumsi obat yang diberikan demi memperbaiki kualitas hidup dan mencegah timbulnya komplikasi lain.

\section{KESIMPULAN}

Berdasarkan hasil penelitian dan analisis yang telah dilakukan, dapat disimpulkan bahwa dari 44 responden dalan penelitian, sebanyak 26 pasien $(59,1 \%)$ patuh terhadap pengobatannya dan 18 pasien tidak patuh $(40,9 \%)$.

\section{DAFTAR PUSTAKA}

Alhaddad, I.A., Hamoui, O., Hammoudeh, A., Mallat, S., 2016, Treatment adherence and quality of life in patients on antihypertensive medications in a Middle eastern population: adherence, Dovepress, 2016:12 407-413.

Anggraini, AD., Waren, S., Situmorang, E., Asputra, H., dan Siahaan, SS., 2009, Faktor-Faktor Yang Berhubungan Dengan Kejadian Hipertensi Pada Pasien 
Yang Berobat Di Poliklinik Dewasa Puskesmas Bangkinang Periode Januari Sampai Juni 2008, Fakultas Kesehatan, Universitas Riau, Files of DrsMed-FK UNRI: $1-41$.

Annisa, 2013, Penilaian Kualitas Hidup pada Usia Lanjut Dengan Eq-5d di Klun Jantung Sehar Kelurahan Pondok Kelapa dan Faktor-Faktor yang Mempengaruhi, Tesis, Fakultas Kedokteran Universitas Indonesia, Jakarta.

Aulia, K., 2016, Studi Interaksi Obat Pada Pasien Geriatri Penderita Hipertensi di Puskesmas Wirobrajan Yogyakarta Periode Desember 2015-Februari 2016, Skripsi, Fakultas Farmasi Universitas Ahmad Dahlan, Yogyakarta.

Bolarinwa, O.A., Ameen, H.A., Sanya, E.O., Kolo, P.M., Durowade, K.A., Uthman, M.D.B., Ogunmodede, J.A., Biliaminu, S.A., Odeigahm L.O., Akande, T.M., 2016, Pattern and Predictive Factors of Health-related Quality of Life of Patients with Hypertension, Diabetes and Concomitant Hypertension with Diabetes in Ilorin, Nigeria, Nigerian Postgraduate Medical Journal, 23 : 182-190.

Carvalho, M.V.D., Siqueira, L.B., Sousa, A.L.L., Jardim, P.C.B.V., 2012, The Influence of Hypertension on Quality of Life, Arq Bras Cardiol, 100(2): 164-174.

Darnindro, N., Sarwono, J., 2017, Prevalensi Ketidakpatuhan Kunjungan Kontrol pada Pasien Hipertensi yang Berobat di Rumah Sakit Rujukan Primer dan FaktorFaktor yang Memengaruhi, Jurnal Penyakit Dalam Indonesia, Vol. 4, No. 3.

Dinas Kesehatan Kota Yogyakarta, 2014, Profil Kesehatan Tahun 2015 Kota Yogyakarta (Data Tahun 2014), Dinas Kesehatan Kota Yogyakarta, Yogyakarta.

Fauzia, 2016, Pengukuran Kualitas Hidup Pasien Hipertensi Di Puskesmas Mergangsan Yogyakarta Menggunakan European Quality Of Life 5 Dimensions (EQ5D) Questionnaire Dan Visual Analog Scale (VAS), Skripsi, Fakultas Farmasi Universitas Ahmad Dahlan, Yogyakarta.

Kementerian Kesehatan Republik Indonesia, 2014, Profil Kesehatan Indonesia Tahun 2013, Kementerian Kesehatan Republik Indonesia, Jakarta.

Kolo, P.M., Jibrin, Y.B., Sanya, E.O., Alkali, M., Kio, I.B.P., Moronkola, R..K., 2012, Hypertension-Related Admissions and Outcome in a Tertiary Hospital in Northeast Nigeria, International Journal of Hypertensio.

Lestari, N.Y., 2015, Validasi European Quality Of Life-5 Dimensions (Eq-5d) Questionnaire Versi Indonesia Pada Pasien Hipertensi Di Puskesmas, Skripsi, Fakultas Farmasi Universitas Ahmad Dahlan, Yogyakarta.

Morello, C.M., Chynoweth, M., Kim, H., Singh, R.F., Hirsch, J.D., 2011, Strategies to Improve Medication Adherence Reported by Diabetes Patients and Caregivers: Result of a Taking Control of Your Diabetes Survey, Ann Pharmacother, Vol.45 No.2, 145-153.

Saputri, G.Z., Dania, H., Faridah I.N., Chusnuni, F.A., 2018, Validation of patient knowledge questionnaire for patients with diabetes mellitus and hyperlipidemia, Pharmaciana, Vol.8, No.2, Nov 2018, Page. 249-256.

Sari, A., Lestari, N.Y., Perwitasari, D.A., 2015, Validasi St European Quality Of Life-5 Dimensions (Eq-5d) Versi Indonesia Pada Pasien Hipertensi Di Puskesmas 
Kotagede II Yogyakarta, Jurnal Ilmiah Nasional Tidak Terakreditasi "Pharma Ciana", Vol. 5 No. 2.

Unadike, B.C., Eregie, A., Ohwovoriole, A.E., 2011, Prevalence of hypertension amongst persons withvdiabetes mellitus in Benin City, Nigeria, Nigerian Journal of Clinical Practice, Vol 14.

Zyoud, S., Al-Jabi, S.W., Sweileh, W.M., Widali, A.H., Saleem, H.M., Aysa, H.A., Badwan, M.A., Awang, R., Merisky, D.E., 2013, Health-related quality of life associated with treatment adherence in patients with Hypertension: a crosssectional-Study, Int J Cardiol, 168(3):2981-3. DOI : 10.1016/j.ijcard.2013.04.105. 